\title{
The Prognosis of Fulminant Hepatic Failure in Pregnant Women due to Hepatitis $\mathrm{E}$
}

\author{
Ajesh Desai, Vijay Kansara, Hina Oza, Pallavi Ninama, Disha Jeetendar Paryani
}

\begin{abstract}
Objectives: Jaundice in pregnancy carries with it a high mortality rate. In this study, we examined the characteristics of women with hepatitis $E$ and assessed whether delivery has any influence on survival of women with hepatitis $E$ due to the stress of labor in terms of multiorgan failure after delivery.
\end{abstract}

Design: A retrospective study of hospital records was done on women of hepatitis E from December 2010 to August 2011 at Civil Hospital, Ahmedabad, India. The women were divided into two groups: expired and survived.

Results: Fatality rate during the epidemic months (March/ April/May) was not significantly different from fatality rates during nonepidemic months (June to February). The overall mortality rate of fulminant hepatic failure was $94 \%$. The mean duration of jaundice, levels of bilirubin, serum glutamic pyruvic transaminase (SGPT), and prothrombin time (PT) were significantly different between two groups. The women with an altered creatinine and PT [International Normalized Ratio (INR) $>1.5$ ] had a high mortality rate of 88 and $76 \%$, respectively. All those who were conscious at the time of delivery (no hepatic encephalopathy) survived while those who were unconscious expired after delivery. All those who were intubated died.

Conclusion: Hepatitis $\mathrm{E}$ is endemic in India and is an important indirect cause of maternal mortality. Study of the expired group helps understand the critical levels of liver function tests. This can help in appropriate counselling of patients and their relatives regarding the prognosis. Although delivery does not have any effect on survival, blood loss, infection and raised intracranial tension can cause liver hypoxia and worsen the disease state.

Keywords: Maternal mortality, Hepatitis E, Jaundice in pregnancy, Fulminant hepatic failure.

How to cite this article: Desai A, Kansara V, Oza H, Ninama $P$, Paryani DJ. The Prognosis of Fulminant Hepatic Failure in Pregnant Women due to Hepatitis E. Euroasian J HepatoGastroenterol 2013;3(2):94-96.

Source of support: Nil

Conflict of interest: None

\section{INTRODUCTION}

Viral hepatitis E carries a mortality of $65.8 \%{ }^{1}$ in India during pregnancy. Hepatitis $\mathrm{E}$ occurs in sporadic, epidemic and endemic forms. Normally, hepatitis E spreads via feco-oral route. It has an incubation period of 40 days. Incidence of fulminant hepatic failure due to hepatitis $\mathrm{E}$ in pregnancy is $22.2 \%{ }^{2}$ Contrary to O'Grady, in India prognosis of acute hepatic failure (AHF) due to viral hepatitis is not affected by the duration of the onset of encephalopathy. ${ }^{3}$ The common causes of death in fulminant hepatic failure in pregnancy are infection, hemorrhage and encephalopathy. Precipitating factors of hepatic encephalopathy aggravated by delivery are blood loss and trauma due to postpartum hemorrhage, raised intracranial tension during labor and infection due to death of fetus. These precipitating factors aggravate liver injury during vaginal delivery and delivery by cesarean section. The following study has been conducted to analyze the critical role of liver function tests and to analyze obstetrician's role in terms of delivery and survival.

\section{MATERIALS AND METHODS}

Thirty-eight women of jaundice coming to the Department of Obstetrics and Gynecology of Civil Hospital at Ahmedabad, Gujarat, India from December 2010 to August 2011 were retrospectively studied. Women with pre-eclampsia, HELLP (hemolysis, elevated liver enzymes and low platelets) syndrome and cholestatic jaundice were excluded. Variables such as age, gravid, month of admission, gestational age, duration of illness, an admission delivery interval, mode of delivery, perinatal data, delivery intubation interval, liver function tests and renal function tests were recorded. The above variables were compared in two groups: group A (expired) and group B (survived). Chi-square $\left(\chi^{2}\right)$ test and Student t-test were used to compare variables and tests were considered significant when $\mathrm{p}$-value $<0.05$.

\section{RESULTS}

In the present study, $84 \%(32 / 38)$ women had hepatitis E. Reports of six women could not be found. They were clinically diagnosed with viral hepatitis E. The 38 women studied were divided into two groups: group A included those who expired and group B included those who survived. Analysis has been done after removing outliers from the data. Group A had 17 women who expired while group B had 21 women who survived.

The age was $24.8 \pm 0.6$ years (mean and standard deviation). The mean age of women who expired is 25.29 years and that of those who survived is 24.52 years; the difference between the two was statistically insignificant $(p=0.28)$.

Figure 1 shows distribution of women presenting with hepatitis E with respect to time of the year. Twenty-four out of $38(63.8 \%)$ women presented during March/April/May showed the emergence of an epidemic. The mortality rate during this quarter of the year was $50 \%$ while during the rest 


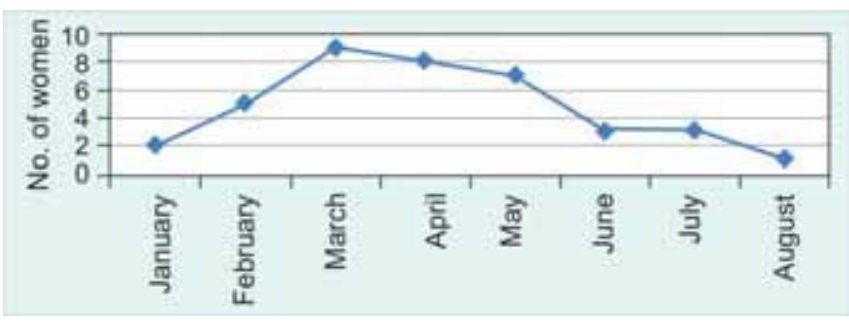

Fig. 1: The month of admission

of the year was $35.7 \%$ which is not statistically significant $(\mathrm{p}=0.39)$.

Twenty-five out of $38(65 \%)$ women presented with 7 to 9 months of amenorrhea. The mean gestational age in group A was 6.7 while in group B was 7.5; the difference in mean gestational age is statistically significant at $10 \%(\mathrm{p}=0.1)$.

Twenty out of 38 patients (55\%) presented with the history of jaundice of $<7$ days duration. Sixty-six percent $(14 / 21)$ of women, presenting with jaundice of duration $<7$ days expired while only $18 \%$ (3/16) with duration of jaundice $>7$ days expired which is statistically significant $(\mathrm{p}=0.04)$.

The mean bilirubin, SGPT, PT INR values of group A were $19.92 \mathrm{mg} / \mathrm{dl}, 720.82 \mathrm{IU} / \mathrm{ml}$ and 2.7 while of group B were $13.83,423.6$ and 1.37 , respectively; all of which are statistically significant $(p=0.03,0.04$ and 0.01 respectively).

Figure 2 show the occurrence of fulminant hepatic failure. Fulminant hepatic failure developed in 18/38 (47\%) women. Seventeen out of 18 (94.4\%) women with hepatic encephalopathy expired. Seventy-two percent (13/18) women of hepatic encephalopathy delivered. Five women died undelivered. The mortality and survival rate differ at $1 \%$ significant level $(\mathrm{p}<0.0001)$. The mean delivery intubation interval of women was 14 hours.

Sixteen out of $28(57 \%)$ women who had delivered expired while $50 \%$ of undelivered expired. This difference is not statistically significant. The mortality rate was not

Delivered

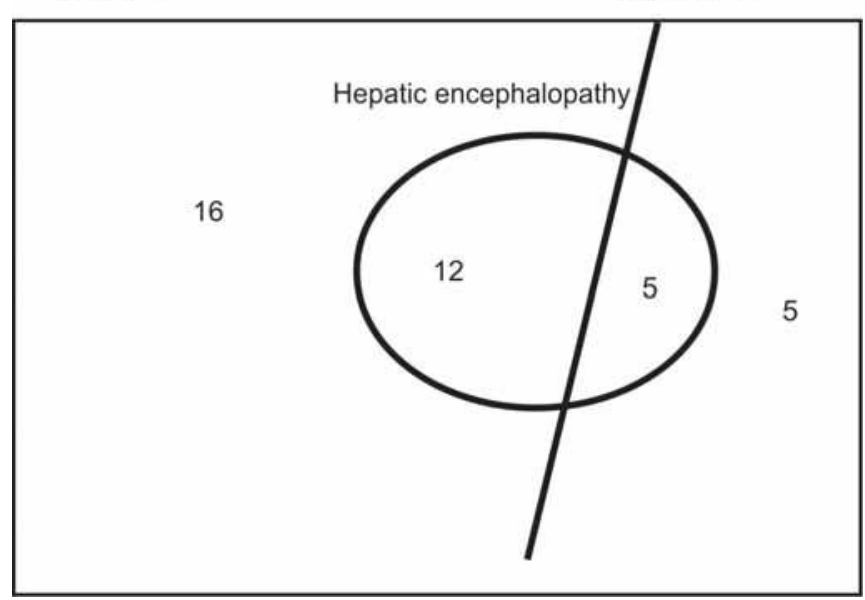

Fig. 2: The occurrence of fulminant hepatic failure significantly different in delivered/undelivered groups. Out of 28 who delivered, all those who developed hepatic encephalopathy before and during delivery expired, while those who were conscious at the time of delivery survived. The mean delivery intubation interval of women was 14 hours. All those who were intubated died.

Eight out of 17 (47\%) women in group A had altered creatinine while only 1 out of $20(0.05 \%)$ in group B had renal failure which was statistically significant. Eighty-eight percent women with altered creatinine expired.

\section{DISCUSSION}

Similar to our study, Acharya ${ }^{4}$ showed that 'age $\geq 40$ years, the presence of cerebral edema, serum bilirubin $\geq 15 \mathrm{mg} / \mathrm{dl}$, and prothrombin time prolongation of 25 seconds or more over controls were independent predictors of the outcome. Ninety-three percent of the women with three or more of the above prognostic markers died. The sensitivity, specificity, positive predictive value, and the negative predictive value of the presence of three or more of these prognostic factors for mortality was $93,80,86$ and $89.5 \%$, respectively, with a diagnostic accuracy of $87.3 \%{ }^{4}$

Since, viral hepatitis assumes fulminancy in pregnancy, termination of pregnancy should theoretically be useful. However, review of literature shows lack of evidence of advantage of termination of pregnancy in viral hepatitis. ${ }^{5}$

According to Banait et al delivery of the survived fetus was associated with improved survival only in case of hepatic encephalopathy. ${ }^{6}$

In a case report, Jia et al recommended termination of pregnancy on the proper time as treatment for severe liver disease. ${ }^{7}$ Shi et al recommended cesarean section as the mode of delivery, followed by peripartum hysterectomy to control postpartum hemorrhage and increased intracranial tension during uterine contractions. ${ }^{8}$

Those with coagulopathy and hepatic encephalopathy (any grade) expire after delivery. Bleeding after delivery and raised intracranial tension during vaginal delivery often lead to hypoxia to liver and worsen hepatic encephalopathy. Hence, it becomes imperative to classify the disease process of any patient as improving or deteriorating for individual patient obstetric and medical management. Various scores include composite assessment of liver function tests like a model for end-stage liver disease (MELD) score which takes into account the S. creatinine, S. bilirubin and PT, acute physiology and chronic health evaluation (APACHE) II score, arterial ketone body ratio ${ }^{9}$ acetoacetate/betahydroxybutyrate as an index of the hepatic energy charge and help to assess disease activity. The women with a deteriorating liver function should be delivered before the 
onset of hepatic encephalopathy and the coagulopathy. Care about precipitating factors of hepatic encephalopathy should be taken during delivery of women with regular arterial blood gas analysis (ABGA), electrolytes and antibiotics. Blood loss should be minimized to avoid hypoxia to liver.

\section{REFERENCES}

1. Jilani N, Das BC, Husain SA, Baweja UK, Chattopadhya D, Gupta RK, Sardana S, Kar P. Hepatitis E virus infection and fulminant hepatic failure during pregnancy. J Gastroenterol Hepatol 2007 May;22(5):676-682.

2. Khuroo MS, Teli MR, Skidmore S, Sofi MA, Khuroo MI. Incidence and severity of viral hepatitis in pregnancy. Am J Med $1981 \mathrm{Feb} ; 70(2): 252-255$.

3. Acharya SK, Panda SK, Saxena A, Gupta SD. Acute hepatic failure in India: a perspective from the East. J Gastroenterol Hepatol 2000 May;15(5):473-479.

4. Acharya SK, Dasarathy S, Kumer TL, Sushma S, Prasanna KS, Tandon A, Sreenivas V, Nijhawan S, Panda SK, Nanda SK, et al. Fulminant hepatitis in a tropical population: clinical course, cause, and early predictors of outcome. Hepatology 1996 Jun;23(6):1448-1455.

5. Navaneethan U, Al Mohajer M, Shata MT. Hepatitis E and pregnancy: understanding the pathogenesis. Liver Int 2008 Nov;28(9):1190-1199.

6. Banait VS, Sandur V, Parikh F, Murugesh M, Ranka P, Ramesh VS, Sasidharan M, Sattar A, Kamat S, Dalal A, et al. Outcome of acute liver failure due to acute hepatitis $\mathrm{E}$ in pregnant women. Indian J Gastroenterol 2007 Jan-Feb;26(1):6-10.

7. Jia ZS, Xie YM, Yin GW, Di JR, Guo WP, Huang CX, Bai XF. Successfully rescuing a pregnant woman with severe hepatitis E infection and postpartum massive hemorrhage. World J Gastroentrol 2003 Mar;9(3):631-632.
8. Shi Z, Li X, Yang Y, Ma L, Schreiber A. Obstetrical management of fulminant viral hepatitis in late pregnancy. Reproductive Sys Sexual Disord 2012;1:102.

9. Scaiola A, MacMathuna P, Langley PG, Gove CD, Hughes RD, Williams R. Determination of the ketone body ratio in fulminant hepatic failure. Hepatogastroenterology 1990 Aug;37(4): 413-416.

\section{ABOUT THE AUTHORS}

\section{Ajesh Desai}

Professor, Department of Obstetrics and Gynecology, GMERS Medical College, Sola, Gujarat, India

\section{Vijay Kansara}

Associate Professor, Department of Obstetrics and Gynecology GMERS Medical College, Sola, Gujarat, India

\section{Hina Oza}

Associate Professor, Department of Obstetrics and Gynecology, BJ Medical College, Ahmedabad, Gujarat, India

\section{Pallavi Ninama}

Associate Professor, Department of Obstetrics and Gynecology, BJ Medical College, Ahmedabad, Gujarat, India

\section{Disha Jeetendar Paryani (Corresponding Author)}

Senior Resident, Department of Obstetrics and Gynecology GMERS Medical College, Sola, Gujarat, India, Phone: 9909020980 e-mail: dishavs_23@hotmail.com 